See discussions, stats, and author profiles for this publication at: https://www.researchgate.net/publication/6223406

\title{
Validating the Body Uneasiness Test (BUT) in obese patients
}

Article in Eating and weight disorders: EWD · July 2007

DOI: 10.1007/BF03327581 - Source: PubMed

\section{CITATIONS}

33

9 authors, including:

\section{Massimo Cuzzolaro}

58 PUBLICATIONS 1,254 CITATIONS

SEE PROFILE

Giovanni Spera

Sapienza University of Rome

156 PUBLICATIONS 4,145 CITATIONS

SEE PROFILE

Some of the authors of this publication are also working on these related projects:

Obesity \& Disability View project

Eating behavior View project
242 PUBLICATIONS 15,915 CITATIONS

SEE PROFILE 


\section{$\underset{\text { RESEARCH }}{\text { ORIGINAlidating the Body Uneasiness Test }}$ PAPER (BUT) in obese patients}

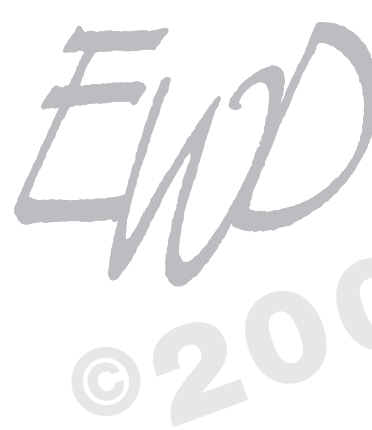

ABSTRACT. OBJECTIVE: To investigate the psychometric properties of the Body Uneasiness Test (BUT) in a large sample of subjects with obesity seeking treatment. BUT is a 71-item self-report questionnaire in two parts: BUT-A which measures weight phobia, body image concerns, avoidance, compulsive self-monitoring, detachment and estrangement feelings towards one's own body (depersonalization); and BUT-B, which looks at specific worries about particular body parts or functions. METHODS: We recruited a clinical sample of 1,812 adult subjects (age range 18-65 years, females 1,411, males 401) with obesity (Body Mass Index, BMI $\geq 30 \mathrm{~kg} / \mathrm{m}^{2}$ ) and a normal weight (BMI value between 18.5 and $25 \mathrm{~kg} / \mathrm{m}^{2}$ ) non-clinical sample of 457 adult subjects (females 248, males 209) with an Eating Attitudes Test-26 (EAT-26) score under the cut-off point 20 (scores $\geq 20$ indicate possible cases of eating disorders). RESULTS: The exploratory and confirmatory analyses confirmed a structural five-factor model for BUT-A and an eight-factor model for BUT-B. Internal consistency was satisfactory. Concurrent validity with Binge Eating Scale (BES) and Three-Factor Eating Questionnaire (TFEQ) was evaluated. The authors calculated mean values for BUT scores in adult (18-65 years) patients with obesity, and evaluated the influence of gender, age and BMI. Females obtained statistically significant higher scores than males in all age groups and in all classes of obesity; patients with obesity, compared with normal weight subjects, generally obtained statistically significant higher scores, but few differences could be attributed to the influence of BMI. CONCLUSION: The BUT can be a valuable multidimensional tool for the clinical assessment of body uneasiness in obesity; the scores of its sub-scales do not show a linear correlation with BMI values.

(Eating Weight Disord. 12: 70-82, 2007). ๑2007, Editrice Kurtis

\section{INTRODUCTION}

Key words:

Body Uneasiness Test, obesity, body image, gender, age, body mass index, Binge Eating Scale, Three-Factor Eating Questionnaire.

Correspondence to: Massimo Cuzzolaro University of Rome La Sapienza, Medical School Policlinico Umberto I, Department of Medical Physiopathology, Obesity and Eating Disorders Unit Viale del Policlinico 155, 00161 Roma, Italy

E-mail:

m.cuzzolaro@flashnet.it

Received: May 18, 2006

Accepted: April 23, 2007 16: 115-124, 2003)
The first systematic studies on body image and body dissatisfaction in subjects with obesity date back to the sixties $(1,2)$ and their clinical relevance has continued to increase in the years (3-9). However, studies in this area are complicated by a variety of conceptual and methodological problems and are relatively few in number.

First of all, body image is a multidimensional psychological construct which includes perceptual, cognitive, emotional, relational, and behavioural components (10).
Many available instruments rely on only one, or few, of its dimensions (11-13): for example global body satisfaction (14-17), negative appreciation of body size, general body dissatisfaction and lack of familiarity with one's own body (18-21), or discrepancy between actual body size and ideal body size $(22,23)$.

Sarwer et al. (8) recently described a second difficulty: "many of the measures (of body satisfaction and related concepts) were developed, normed and validated on college students. Certainly these samples contained some proportions of overweight or obese individuals; however studies often have
${ }^{1}$ A complete list of participants in the QUOVADIS study has been previously published (Diab Nutr Metab 
failed to provide information on the body mass of the respondents or to evaluate the psychometric characteristics of the scales that assessed body weight. Similarly the psychometric qualities of the scales developed on nonpatient samples may not generalize to patient samples".

Finally, in the area of obesity studies, a third difficulty is linked to the composition of samples. The obesity galaxy is enormous and heterogeneous: it is well known that such factors as gender, age, onset age of overweight, degree of obesity, ethnicity, social class, history of childhood teasing and parental criticism about weight, history of weight cycling, and presence of binge eating all show important modulating effects on body uneasiness (6-8).

With regard to these problems, as Sarwer et al. wrote in the above cited paper, many of the studies on body image "used truncated distributions of overweight and obese individuals, typically excluding those with extreme obesity. Studies investigating large samples of individuals with a wide range of BMIs (body mass index) are needed to clarify the relationship between body mass and body image dissatisfaction" (8).

For these reasons we decided to investigate the psychometric properties of the Body Uneasiness Test (BUT), a new questionnaire (24), in a large sample of patients (males and females of different age groups, resident in several Italian regions), with I, II or III class of obesity. The questionnaire was developed with the specific aim of investigating not only body dissatisfaction, but also other dimensions of socalled negative body image (25).

The BUT was initially validated on a large general population sample of 3,273 subjects (2,016 females) of different age groups, with $\mathrm{BMI}<25 \mathrm{~kg} / \mathrm{m}^{2}$ and eating attitudes test (EAT26) scores under the cut-off point 20 (scores higher indicate possible cases of eating disorders) (26-29). The BUT questionnaire had also been validated in a clinical sample of 531 subjects (491 females) of different age groups with Anorexia Nervosa or Bulimia Nervosa according to DSM-IV-TR criteria (30). In the last few years, some other studies have used the BUT to examine ballet dancers, gymnasium attendees and body builders (31), women with premenstrual dysphoric disorder (32), patients with eating disorders (33), binge eating disorder (20), and obesity (34-37), but no studies of systematic validation of the questionnaire on treatment-seeking subjects with BMI $\geq 30 \mathrm{~kg} / \mathrm{m}^{2}$ have been performed until now.

The first aim of the present study was to investigate the factor structure and the internal consistency of the BUT in a large sample of subjects with obesity.
The second aim was to evaluate the concurrent and discriminant validity in comparison with two rating scales frequently used to study eating behaviour in obesity: Binge Eating Scale, BES (38) and Three-Factor Eating Questionnaire (TFEQ) (39).

The third aim was to calculate the mean BUT scores in adult (18-65 years) patients with obesity, of both genders, and to evaluate the influence of gender, age and BMI.

\section{METHOD}

Participants

We studied a clinical sample of 1,812 (1,411 females and 401 males) adult subjects (age range 18-65 years) with obesity (group A) and a normal weight (NW) non-clinical sample of 457 (248 females and 209 males) adult subjects with a BMI value between 18.5 and $25 \mathrm{~kg} / \mathrm{m}^{2}$ and an Eating Attitudes Test-26 (EAT-26) score under the cut-off point 20 (scores higher indicate possible cases of eating disorders) (27) (group B).

The obese patients (group A) were participating in the QUOVADIS Study, a large Italian observational study on quality of life, body image, psychological distress and eating behaviour in obese patients seeking treatment at twenty-five medical centres, accredited by the Italian Health Service for the treatment of obesity (40). All adult individuals with obesity (age $>18$ years, BMI $\geq 30 \mathrm{~kg} / \mathrm{m}^{2}$ ) consecutively seeking treatment were eligible for the study, provided they were not on active treatment at the time of enrollment and agreed to complete self-administered questionnaires. Data were stored in a large database, accessed by individual centres through an extranet system and electronic forms.

We divided this group into three subgroups according to current classifications of obesity (41-43): Class I (BMI 30-34.9), Class II (BMI 3539.9) and Class III (BMI $\geq 40$ ).

Group B was extracted from the general sample used for the previous validation of the BUT (24), matched for age class and educational qualification with group A. Group B was also made up of subjects resident in different regions in the north, centre and south of Italy.

Table 1 shows the age and BMI values (means and standard deviations) of the total sample and of the different subgroups.

\section{Measures}

Weight and height

A physician measured each patient's weight on a medical-balance and height by a stadiometer while patients were in their underwear without shoes. 


\begin{tabular}{|c|c|c|c|c|c|c|}
\hline & & & $\begin{array}{l}\text { TABLE } \\
\text { Samples }\end{array}$ & & & \\
\hline & & $N$ & & ge & & \\
\hline Males & NW & 209 & 35.93 & \pm 7.06 & 24.33 & \pm 1.93 \\
\hline & Ob-1 & 164 & 44.63 & \pm 10.71 & 32.43 & \pm 1.34 \\
\hline & $O b-11$ & 112 & 45.52 & \pm 10.12 & 37.36 & \pm 1.65 \\
\hline & Ob-III & 125 & 43.80 & \pm 9.94 & 45.74 & \pm 4.82 \\
\hline & M total & 610 & 41.64 & \pm 10.36 & 33.28 & \pm 7.61 \\
\hline Females & NW & 248 & 37.46 & \pm 8.79 & 21.56 & \pm 2.66 \\
\hline & Ob-I & 523 & 46.20 & \pm 11.07 & 32.40 & \pm 1.40 \\
\hline & Ob-II & 406 & 45.59 & \pm 10.22 & 37.10 & \pm 1.41 \\
\hline & Ob-III & 482 & 45.26 & \pm 10.12 & 45.33 & \pm 5.21 \\
\hline & F total & 1659 & 44.47 & \pm 10.59 & 35.69 & \pm 7.30 \\
\hline Total & NW & 457 & 36.75 & \pm 8.05 & 22.84 & \pm 2.73 \\
\hline & $O b-1$ & 687 & 45.82 & \pm 10.99 & 32.41 & \pm 1.39 \\
\hline & Ob-II & 518 & 45.57 & \pm 10.19 & 37.16 & \pm 1.44 \\
\hline & Ob-III & 607 & 44.96 & \pm 10.10 & 45.42 & \pm 5.14 \\
\hline & $M \& F$ total & 2269 & 43.70 & \pm 10.57 & 35.04 & \pm 7.41 \\
\hline
\end{tabular}

BMI: Body mass index; NW: normal weight; Ob-I, Ob-II, OB-III: obesity class I, II, III

\section{Psychometric measures}

We used three questionnaires: Body Uneasiness Test (BUT) $(24,44,45)$; Binge Eating Scale (BES) (38) and TFEQ (39).

The BUT is a self-administered questionnaire specifically designed to explore several areas in clinical and non-clinical populations: body shape and/or weight dissatisfaction, avoidance, compulsive control behaviours, detachment and estrangement feelings towards one's own body, specific worries about particular body parts, shapes or functions. The BUT consists of two parts: BUT-A (34 items) and BUT-B (37 items). In keeping with the previous validation studies $(24,44,45)$ the BUT-A scores were combined in a global severity index (GSI) and in 5 sub-scales resulting from factorial analysis: Weight phobia (WP - fear of being or becoming fat), body image concerns (BIC -worries related to physical appearance), Avoidance (A - body imagerelated avoidance behaviour), compulsive selfmonitoring (CSM - compulsive checking of physical appearance), and Depersonalization (D - detachment and estrangement feelings toward the body); BUT-B scores were combined in two global measures (positive symptom total, PST and positive symptom distress index, PSDI) and in eight factors that examine specific worries about particular sets of body parts or functions (Appendixes 1 and 2) Higher scores indicate greater body uneasiness.
The English version of the BUT can be found in Appendix 1. The Italian and the French versions of the test are available from the Authors on request. Scoring instructions are reported in Appendix 2.

The Binge Eating Scale (BES) measures the severity of binge eating (38). It examines both behavioural signs (eating large amounts of food) and feelings or cognitions during a binge episode (loss of control, guilt, and fear of being unable to stop eating).

The TFEQ is a 51 -item self-report questionnaire that measures three factors: I, Cognitive control of eating or restriction; II, Disinhibition; III, Susceptibility to hunger or hunger (39).

The tests were administered in a self-report fashion (i.e., the investigators did not assist the subjects in the compilation of the questionnaires).

The protocol of this multicenter study was approved by the ethical committees of the individual centres, after approval by the ethical committee of the coordinating centre (Azienda Ospedaliera di Bologna, Policlinico S. OrsolaMalpighi). All participants gave written informed consent for participation.

\section{Data analyses}

The 34 items of BUT-A and the 37 items of BUT-B were subjected to a confirmatory factor analysis to find the structural equation model that best fitted the data. The structure of each sub-scale was assessed by using PCA (principal component analysis). Internal consistency of each domain was assessed using Cronbach Alpha coefficients. Item to domain correlations were also calculated in order to evaluate to what extent each item was associated with its domain (or with another competing scale). Furthermore, the mean correlation between each item and the total of other scales was calculated.

To assess the predictive validity for gender, age and BMI we carried out a set of analyses of variance (ANOVA) on the scores obtained in the GSI and in all the BUT-B and BUT-A sub-scales by males and females of different age groups and BMI classes. Contrast analyses were also carried out for all the sub-scales, considering the interactions with at least $\mathrm{p}<0.05$ significant.

In order to measure and remove the effects of the BMI scores on those of the BUT sub-scales, a set of analyses of covariance was carried out: in each analysis we used a BUT-A or a BUT-B sub-scale as dependent variable, gender and age group (levels: $1=18-39 ; 2=40-49 ; 3=50-65$ ) as factors, the BMI score as covariate.

Finally, to evaluate the capacity of the BUT to single out the presence/absence of obesity, using the scores of all the BUT sub-scales, we performed a discriminant analysis comparing sub- 
jects with obesity with a control group of NW subjects of the same gender and age group; we also performed a second discriminant analysis to evaluate the capacity of the BUT to single out subjects of the same gender and of the same age group belonging to different classes of obesity, using all the BUT sub-scales. We used the stepwise method: at each step the variable that minimizes the overall Wilks lambda was entered.

The analyses were performed using SPSS 10.0 (SPSS, San Diego, CA) and JMP 6.0.3 (SAS Institute, Cary, NC).

\section{RESULTS}

Factor structure and internal consistency

To assess the factorial structure of the questionnaire in patients with obesity we carried out a confirmatory factor analysis using the data from Group A. The analysis confirmed the structural five-factor model for BUT-A which had already emerged in the 2006 study. The five factors are defined as follows:

- WP: Weight Phobia (fear of being or becoming fat)

- BIC: Body Image Concerns (over-concern with physical appearance)

- A: Avoidance (avoidance behaviour related to body image)

- CSM: Compulsive Self-monitoring (compulsive checking of physical appearance)

- D: Depersonalization (detachment and estrangement feelings towards the body)

In the same way, as far as BUT-B is concerned, the confirmatory factor analysis confirmed the structural model with the eight factors that had already emerged.

The eight BUT-B factors are represented by Roman numerals:

- I (eyebrow, eyes, nose, mouth, lips, teeth)

- II (shape of the head, shape of the face, forehead, ears, chin, neck)

- III (stomach, abdomen, hips, thighs, knees)

- IV (stature, legs, ankles, feet, hands)

\section{TABLE 2}

Confirmatory factorial analysis; test of the model based on the proposed BUT-A and BUT-B scales.

\begin{tabular}{lccccccc|} 
& \multicolumn{2}{c}{$\begin{array}{c}90 \% \text { lower } \\
\text { conf. Int }\end{array}$} & \multicolumn{2}{c}{$\begin{array}{c}\text { Punctual } \\
\text { estimate }\end{array}$} & \multicolumn{2}{c}{$\begin{array}{c}90 \% \text { upper } \\
\text { conf. int }\end{array}$} \\
& BUT-A & BUT-B & BUT-A & BUT-B & BUT-A & BUT-B \\
\hline $\begin{array}{l}\text { Steiger-Lind's } \\
\text { RMSEA index }\end{array}$ & 0.035 & 0.050 & 0.056 & 0.051 & 0.087 & 0.053 \\
\hline $\begin{array}{l}\text { Adjusted population's } \\
\text { gamma index }\end{array}$ & 0.914 & 0.934 & 0.941 & 0.940 & 0.963 & 0.948 \\
\hline
\end{tabular}

\begin{tabular}{|lcc|}
\multicolumn{4}{c}{ TABLE 3 } & \\
Homogeneity and internal consistency. \\
\hline Subscale & Mean CITC & Cronbach \\
\hline BUT-A Weight phobia & 0.69 & 0.85 \\
\hline BUT-A Body image concern & 0.74 & 0.89 \\
\hline BUT-A Avoidance & 0.75 & 0.84 \\
\hline BUT-A Compulsive self-monitoring & 0.66 & 0.75 \\
\hline BUT-A Depersonalization & 0.77 & 0.84 \\
\hline BUT-B I & 0.78 & 0.73 \\
\hline BUT-B II & 0.67 & 0.75 \\
\hline BUT-B III & 0.77 & 0.84 \\
\hline BUT-B IV & 0.69 & 0.74 \\
\hline BUT-B V & 0.71 & 0.76 \\
\hline BUT-B VI & 0.83 & 0.76 \\
\hline BUT-B VII & 0.82 & 0.64 \\
\hline BUT-B VIII & 0.69 & 0.72 \\
\hline
\end{tabular}

- V (arms, shoulders, chest, breasts, genitals)

- VI (moustache, beard, hairs)

- VII (hair, skin)

- VIII (sweating, blushing, noises, odours, buttocks).

These results are shown in Table 2.

We tested several models, each with and without the possibility of correlation between factors. The model based on the factors derived from the previous general validation study (24) was confirmed as the most suitable one. The model fits the data only when allowing the factors to be correlated. The correlations predicted by the model are almost exactly correspondent to the previously observed ones.

The BUT's internal consistency (Table 3) seems to be satisfactory in terms of both the significant homogeneity (indicated by the ItemTotal Correlations) and the clearly one-dimensional structure shown by each of the subscales according to the Principal Components Analysis. The levels of Cronbach's alpha coefficients range between 0.64 (only BUT-B VII, a factor that contains only two items) and 0.89 : all the sub-scales but one showed Cronbach's alpha coefficients greater than 0.7. Therefore, internal consistency appears good $(11,46)$.

\section{Concurrent and discriminant validity}

In the group A subjects, a principal components analysis with varimax rotation was carried out on the scores of all the sub-scales of the BUT, on the total score of the BES and on the scores of the three sub-scales of the TFEQ: 


\section{TABLE 4}

BUT, BES and TFEQ. Principal components analysis.

\begin{tabular}{lccc} 
& I & $\begin{array}{c}\text { Components } \\
\text { II }\end{array}$ & III \\
\hline BUT-A BIC & 0.887 & 0.171 & 0.099 \\
\hline BUT-A WP & 0.882 & 0.139 & 0.057 \\
\hline BUT-A D & 0.833 & 0.187 & 0.122 \\
\hline BUT-A A & 0.821 & 0.166 & 0.136 \\
\hline BUT-A CSM & 0.762 & 0.096 & 0.010 \\
\hline BUT B III & 0.692 & 0.378 & 0.048 \\
\hline BUT B IV & 0.543 & 0.528 & 0.020 \\
\hline BUT B V & 0.542 & 0.533 & 0.016 \\
\hline BUT B I & 0.103 & 0.804 & 0.079 \\
\hline BUT B II & 0.201 & 0.775 & 0.006 \\
\hline BUT B VII & 0.061 & 0.721 & 0.062 \\
\hline BUT B VIII & 0.498 & 0.527 & 0.106 \\
\hline BUT B VI & 0.122 & 0.472 & 0.033 \\
\hline TFEQ hunger & 0.156 & 0.055 & 0.847 \\
\hline TFEQ disinhibition & 0.229 & 0.030 & 0.831 \\
\hline TFEQ restriction & 0.171 & -0.046 & -0.595 \\
\hline BES & 0.363 & 0.083 & 0.387 \\
\hline
\end{tabular}

Table 4 shows the three factors that emerged, which accounted for $60.3 \%$ of the variance.

The BUT-A sub-scales constituted the first principal component and were associated with the BES, but not with the TFEQ sub-scales.

As regards the BUT-B, the sub-scale III was associated only with the BUT-A sub-scales, the I, II,VI and VII sub-scales were associated only with the second principal component, the IV, V, and VIII sub-scales were associated both with the BUT-A sub-scales and the second principal component.

The TFEQ sub-scales were associated only with the third component.

The BES scale was associated both with the first and the third component.

Predictive validity for gender, age and BMI

Tables 5 and 6 show the scores obtained by males and females on the different BUT-A and BUT-B sub-scales for the different age groups and classes of BMI.

The analyses of variance (ANOVA) carried out to assess the predictive validity of the BUT for gender, age and BMI produced the following results.

BUT-A:

- with regard to gender, in the whole sample (NW and obese subjects) females obtained significantly higher scores than males in the GSI and in all the sub-scales

- with regard to the different age groups, both males and females aged 18-39 and 4049 , obtained significantly higher scores than subjects aged 50-65 in the GSI, the WP subscale and the BIC sub-scale

\section{TABLE 5}

BUT-A scores in normal weight and obese subjects.

\begin{tabular}{|c|c|c|c|c|c|c|c|c|c|c|c|}
\hline \multicolumn{4}{|c|}{$18-39$} & \multicolumn{4}{|c|}{$40-49$} & \multicolumn{4}{|c|}{$50-65$} \\
\hline NW & Ob-I & Ob-II & Ob-III & NW & Ob-I & Ob-II & Ob-III & NW & Ob-I & 0 & Ob-II \\
\hline
\end{tabular}

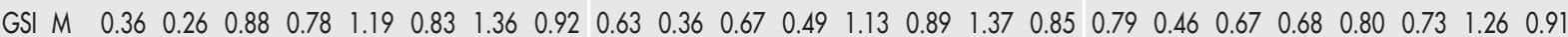

$\begin{array}{lllllllllllllllllllllllllllllll}F & 0.69 & 0.38 & 1.55 & 0.93 & 1.92 & 0.97 & 2.22 & 0.97 & 0.85 & 0.51 & 1.60 & 0.95 & 1.79 & 1.02 & 2.08 & 0.97 & 0.73 & 0.52 & 1.31 & 0.86 & 1.61 & 0.95 & 1.81 & 1.04\end{array}$

$\begin{array}{llllllllllllllllllllllllll}\text { WP M } & 0.66 & 0.50 & 1.27 & 0.99 & 1.52 & 0.95 & 1.79 & 1.26 & 1.04 & 0.53 & 0.96 & 0.71 & 1.45 & 1.14 & 1.81 & 1.06 & 0.94 & 0.44 & 0.90 & 0.83 & 1.12 & 0.97 & 1.69 & 1.10\end{array}$

$\begin{array}{llllllllllllllllllllllllll}F & 1.17 & 0.73 & 2.04 & 1.18 & 2.37 & 1.09 & 2.66 & 1.11 & 1.34 & 0.83 & 2.00 & 1.12 & 2.20 & 1.27 & 2.49 & 1.10 & 0.99 & 1.00 & 1.73 & 1.09 & 1.91 & 1.12 & 2.10 & 1.17\end{array}$

BIC M $\begin{array}{llllllllllllllllllllllllllllll}0.38 & 0.34 & 1.33 & 0.98 & 1.92 & 1.16 & 2.07 & 1.13 & 0.72 & 0.45 & 1.12 & 0.76 & 1.63 & 1.10 & 2.09 & 1.19 & 0.89 & 0.31 & 1.03 & 0.97 & 1.26 & 1.02 & 1.88 & 1.20\end{array}$

$\begin{array}{lllllllllllllllllllllllllllllll}F & 0.81 & 0.51 & 2.21 & 1.16 & 2.77 & 1.18 & 3.14 & 1.14 & 1.03 & 0.61 & 2.22 & 1.16 & 2.40 & 1.17 & 2.81 & 1.07 & 0.89 & 0.65 & 1.80 & 1.06 & 2.26 & 1.15 & 2.48 & 1.19\end{array}$

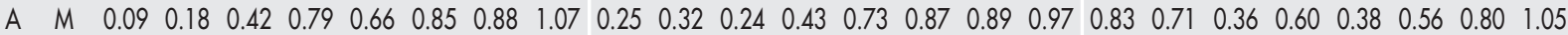

$\begin{array}{llllllllllllllllllllllllllllll}F & 0.23 & 0.33 & 0.99 & 0.99 & 1.37 & 1.25 & 1.64 & 1.22 & 0.42 & 0.51 & 1.12 & 1.06 & 1.36 & 1.16 & 1.66 & 1.24 & 0.42 & 0.52 & 0.92 & 0.94 & 1.21 & 1.10 & 1.51 & 1.24\end{array}$

$\begin{array}{llllllllllllllllllllllllll}\text { CSMM } & 0.39 & 0.36 & 0.54 & 0.64 & 0.62 & 0.74 & 0.64 & 0.63 & 0.63 & 0.45 & 0.35 & 0.38 & 0.68 & 0.70 & 0.60 & 0.64 & 1.00 & 0.71 & 0.41 & 0.58 & 0.49 & 0.64 & 0.71 & 0.71\end{array}$

F $\begin{array}{llllllllllllllllllllllllllll}0.68 & 0.54 & 0.99 & 0.95 & 1.15 & 0.86 & 1.26 & 0.89 & 0.80 & 0.51 & 1.03 & 0.85 & 1.09 & 0.81 & 1.27 & 0.98 & 0.79 & 0.54 & 0.90 & 0.78 & 1.04 & 0.89 & 1.08 & 0.95\end{array}$

$\begin{array}{lllllllllllllllllllllllllll}D & M & 0.16 & 0.37 & 0.40 & 0.77 & 0.70 & 0.90 & 0.83 & 1.00 & 0.26 & 0.32 & 0.28 & 0.46 & 0.72 & 1.00 & 0.84 & 1.01 & 0.10 & 0.14 & 0.33 & 0.64 & 0.35 & 0.74 & 0.65 & 0.87\end{array}$

$\begin{array}{lllllllllllllllllllllllllllllll}F & 0.26 & 0.38 & 0.96 & 1.03 & 1.30 & 1.18 & 1.72 & 1.36 & 0.34 & 0.53 & 1.13 & 1.18 & 1.37 & 1.28 & 1.57 & 1.28 & 0.30 & 0.55 & 0.75 & 0.96 & 1.10 & 1.11 & 1.37 & 1.31\end{array}$

$\mathrm{NW=normal} \mathrm{weight;} \mathrm{Ob-l=class} \mathrm{I} \mathrm{obesity;} \mathrm{Ob-II=class} \mathrm{II} \mathrm{obesity;} \mathrm{Ob-III=class} \mathrm{III} \mathrm{obesity}$ 
TABLE 6

BUT-B scores in normal weight and obese subjects.

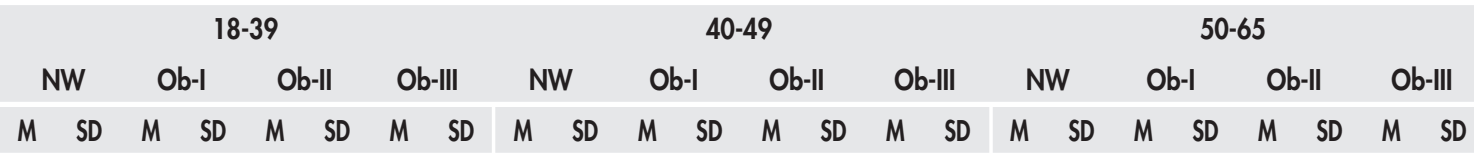

\begin{tabular}{lllllllllllllllllllllllllllll}
\hline & $M$ & 0.31 & 0.33 & 0.26 & 0.38 & 0.24 & 0.35 & 0.22 & 0.32 & 0.46 & 0.38 & 0.36 & 0.57 & 0.32 & 0.36 & 0.23 & 0.42 & 0.42 & 0.12 & 0.19 & 0.28 & 0.16 & 0.28 & 0.47 & 1.13
\end{tabular}

$\begin{array}{lllllllllllllllllllllllllllll}F & 0.46 & 0.56 & 0.27 & 0.50 & 0.41 & 0.59 & 0.38 & 0.49 & 0.54 & 0.68 & 0.53 & 0.70 & 0.39 & 0.56 & 0.37 & 0.65 & 0.44 & 0.38 & 0.45 & 0.68 & 0.48 & 0.74 & 0.57 & 0.81\end{array}$

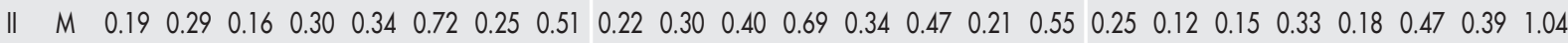

F $\begin{array}{lllllllllllllllllllllllllllll}0.19 & 0.28 & 0.28 & 0.45 & 0.25 & 0.39 & 0.48 & 0.67 & 0.23 & 0.34 & 0.37 & 0.62 & 0.37 & 0.64 & 0.43 & 0.64 & 0.00 & 0.00 & 0.32 & 0.58 & 0.40 & 0.63 & 0.48 & 0.77\end{array}$

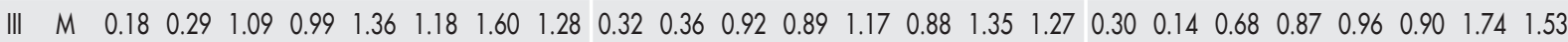

$\begin{array}{lllllllllllllllllllllllllllll}F & 0.73 & 0.64 & 2.15 & 1.44 & 2.81 & 1.55 & 3.15 & 1.43 & 0.91 & 0.73 & 2.24 & 1.39 & 2.21 & 1.44 & 2.81 & 1.57 & 0.68 & 0.60 & 1.74 & 1.43 & 2.04 & 1.46 & 2.50 & 1.56\end{array}$

IV $\quad \begin{array}{lllllllllllllllllllllllllllll} & 0.26 & 0.33 & 0.26 & 0.48 & 0.37 & 0.54 & 0.54 & 0.94 & 0.28 & 0.26 & 0.29 & 0.42 & 0.43 & 0.59 & 0.40 & 0.67 & 0.30 & 0.14 & 0.20 & 0.40 & 0.26 & 0.67 & 0.77 & 1.23\end{array}$

$\begin{array}{llllllllllllllllllllllllllllll}F & 0.66 & 0.76 & 1.08 & 0.90 & 1.51 & 1.13 & 1.72 & 1.19 & 0.68 & 0.78 & 1.29 & 1.12 & 1.23 & 1.17 & 1.53 & 1.24 & 0.53 & 0.66 & 1.02 & 1.07 & 1.14 & 1.16 & 1.50 & 1.29\end{array}$

$\begin{array}{llllllllllllllllllllllllll}V & M & 0.16 & 0.28 & 0.32 & 0.54 & 0.46 & 0.56 & 0.67 & 0.98 & 0.23 & 0.41 & 0.31 & 0.62 & 0.65 & 0.85 & 0.51 & 0.82 & 0.00 & 0.00 & 0.23 & 0.51 & 0.27 & 0.63 & 0.57 & 0.96\end{array}$

$\begin{array}{llllllllllllllllllllllllllll}F & 0.29 & 0.38 & 0.86 & 0.92 & 1.15 & 1.05 & 1.50 & 1.25 & 0.61 & 0.72 & 1.00 & 1.16 & 1.01 & 1.07 & 1.32 & 1.20 & 0.10 & 0.28 & 0.70 & 0.90 & 0.91 & 1.07 & 1.17 & 1.18\end{array}$

$\begin{array}{lllllllllllllllllllllllllllll}\mathrm{VI} & \mathrm{M} & 0.31 & 0.50 & 0.38 & 0.82 & 0.49 & 0.74 & 0.28 & 0.85 & 0.25 & 0.51 & 0.14 & 0.56 & 0.24 & 0.71 & 0.16 & 0.79 & 0.33 & 0.47 & 0.09 & 0.31 & 0.37 & 1.10 & 0.35 & 1.17\end{array}$

$\begin{array}{lllllllllllllllllllllllllllll}F & 0.77 & 0.85 & 0.76 & 1.22 & 0.78 & 1.24 & 0.85 & 1.32 & 0.36 & 0.62 & 0.63 & 1.16 & 0.70 & 1.18 & 0.60 & 1.11 & 0.25 & 0.50 & 0.54 & 1.14 & 0.54 & 1.08 & 0.65 & 1.15\end{array}$

VII $\quad \begin{array}{lllllllllllllllllllllllllllll} & 0.52 & 0.71 & 0.39 & 0.72 & 0.43 & 0.84 & 0.32 & 0.80 & 0.39 & 0.61 & 0.55 & 0.93 & 0.52 & 0.78 & 0.26 & 0.55 & 1.00 & 0.00 & 0.34 & 0.67 & 0.26 & 0.49 & 0.44 & 1.06\end{array}$

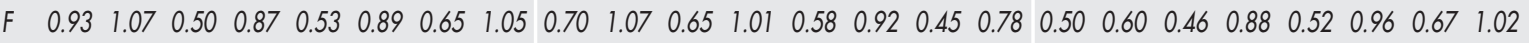

$\begin{array}{lllllllllllllllllllllllllll}\text { VIII M } & 0.35 & 0.42 & 0.79 & 0.76 & 0.86 & 0.78 & 1.20 & 1.06 & 0.83 & 0.76 & 0.56 & 0.80 & 0.84 & 0.98 & 0.89 & 1.06 & 0.20 & 0.28 & 0.57 & 0.69 & 0.66 & 0.94 & 1.06 & 1.29\end{array}$

$\begin{array}{lllllllllllllllllllllllllll}F & 0.75 & 0.81 & 1.05 & 0.90 & 1.37 & 1.01 & 1.75 & 1.16 & 0.60 & 0.73 & 1.16 & 1.03 & 1.32 & 1.16 & 1.70 & 1.25 & 0.85 & 0.81 & 1.11 & 1.09 & 1.28 & 1.20 & 1.58 & 1.29\end{array}$

$\mathrm{NW}=$ normal weight; Ob-I = class I obesity; Ob-II = class II obesity; Ob-III = class III obesity

- with regard to the different BMI classes, Table 7 shows the results of the contrast analyses carried out on the scores of the GSI and on those of all the sub-scales in

\begin{tabular}{|c|c|c|c|c|}
\hline \multicolumn{5}{|c|}{$\begin{array}{c}\text { TABLE } 7 \\
\text { BUT-A (ANOVA). }\end{array}$} \\
\hline & & $18-39$ & $40-49$ & $50-65$ \\
\hline \multirow[t]{2}{*}{ GSI } & M & $N W<[I<(I I, I I I)]$ & $(\mathrm{NW}, \mathrm{I})<(\mathrm{II}, \mathrm{III})$ & $(N W, I, I I)<I I I$ \\
\hline & $\mathrm{F}$ & $N W<I<I \mid<I I I$ & $N W<[(I, I I)<1 I I]$ & $N W<I<I \mid<I I I$ \\
\hline \multirow[t]{2}{*}{ WP } & M & $N W<[I<(I I, I I)]$ & $(N W, I)<(I I, I I I)$ & $(N W, I)<(I I, I I I)$ \\
\hline & $\mathrm{F}$ & $N W<[I<(I I, I I I)]$ & $N W<I<\|<I I I$ & $N W<[I I,(I<I I I)]$ \\
\hline \multirow[t]{2}{*}{$\mathrm{BIC}$} & M & $N W<[I I,(I<I I I)]$ & (NW, II) < (II, III) & $(N W, I, I I)<1 I I$ \\
\hline & $\mathrm{F}$ & $N W<I<I \mid<I I I$ & $N W<[(I, I I)<1 I I]$ & $N W<I<I I<I I I$ \\
\hline \multirow[t]{2}{*}{ A } & M & $N W<[I I,(I<I I I)]$ & (NW, II) < (III, III) & $(I, I I)<(N W, I I I)$ \\
\hline & $\mathrm{F}$ & $N W<I<I \mid<I I I$ & $N W<[(I, I I)<I I I]$ & $N W<I<I I<I I I$ \\
\hline \multirow[t]{2}{*}{ CSM } & M & (NW, II) < (II, III) & $\mathrm{I}<(\mathrm{NW}, \mathrm{II}, \mathrm{III})$ & (NW, III), (I< < III) \\
\hline & $\mathrm{F}$ & $N W<[I I,(I<I I I)]$ & II, [(NW, I) < III] & $(N W, I)<(I I, I I I)$ \\
\hline \multirow[t]{2}{*}{ D } & M & $N W<[I I,(I<\mid I I I)]$ & $(\mathrm{NW}, \mathrm{I})<(\mathrm{II}, \mathrm{III})$ & $(N W, I, I I)<1 I I$ \\
\hline & $\mathrm{F}$ & $N W<I<I \mid<I I I$ & II, [(NW, I) < III] & II, [(NW, I) < III] \\
\hline
\end{tabular}

the different age groups, in males and females.

BUT-B:

- as regards the gender, in the whole sample (NW and obese subjects), females obtained significantly higher scores than males in all the sub-scales.

- as regards the different age groups, both males and females aged 50-65 obtained significantly lower scores in the sub-scale III than subjects aged 18-39 and 40-49 (no significant difference between these groups). Both males and females aged 18-39 obtained significantly lower scores than subjects aged 40-49 and 50-65 (no significant difference between these groups) in the sub-scale VI. In the sub-scale I the interaction between age groups and obesity classes was significant, in that NW females aged 18-39 obtained lower scores than all the obese females; in other age groups, however, there are not statistically significant differences.

- as regards the different BMI classes, Table 8 shows the results of the contrast analyses carried out on the scores of all sub-scales in the different age groups, in males and females.

The results of the analyses of covariance 
show that in males of all age groups there are statistically significant effects of the BMI values on the scores of all BUT sub-scales with the following exceptions:

- in the 18-39 age group: the BIC BUT-A sub-scale and the III and VIII BUT-B subscales

- in the 50-65 age group: the BIC and the D BUT-A sub-scales and the VIII BUT-B subscale.

By contrast, in females there are not statistically significant effects of the BMI values on the scores of all BUT sub-scales, with the following exceptions:

- in the 18-39 age group: the CSM BUT-A sub-scale and the II, V and VII BUT-B subscales

- in the 40-49 age group: the GSI sub-scale, the WP, A and CSM BUT-A sub-scale and the VIII BUT-B sub-scales

- in the 50-65 age group: the CSM BUT-A sub-scale.

Only the following results, however, showed a $95 \%$ confidence interval which permits that they could be extended to the general population:

As regards males:

- BUT-A GSI in the age group 50-65

- BUT-A A sub-scale in the age groups 18-39 and 50-65

- BUT-B factor $\mathrm{V}$ in the age groups 40-49 and 50-65

As regards females:

- BUT-A GSI in the age group 18-39

- BUT-A BIC and A in the age group 40-49

- BUT-B factor III in the age groups 18-39 and 40-49

- BUT-B factor IV in the age groups 40-49 e 50-65

- BUT-B factor $\mathrm{V}$ in the age group 40-49.

Table 9 shows the results of the first discriminant analysis, carried out to evaluate the capacity of the BUT to single out the presence/ absence of obesity.

The second discriminant analysis, carried out to evaluate the capacity of the BUT to single out subjects of the same gender and of the

\begin{tabular}{|c|c|c|c|c|}
\hline \multicolumn{5}{|c|}{$\begin{array}{c}\text { TABLE } 8 \\
\text { BUT-B (ANOVA). }\end{array}$} \\
\hline & & $18-39$ & $40-49$ & $50-65$ \\
\hline \multirow[t]{2}{*}{ I } & $M$ & NW, I, II, III & NW, I, II, III & NW, I, II, III \\
\hline & $\mathrm{F}$ & NW, I, II, III & NW, I, II, III & NW, I, II, III \\
\hline \multirow[t]{2}{*}{$\|$} & $M$ & NW, I, II, III & NW, I, II, III & NW, I , II, III \\
\hline & $\mathrm{F}$ & $(N W, I, I I)<I I I$ & NW, I , II , III & NW, I, II, III \\
\hline \multirow[t]{2}{*}{ III } & M & $N W<[I I,(I<I I I)]$ & $N W<[I I,(I<I I)]$ & NW, I, II, III \\
\hline & $\mathrm{F}$ & $N W<I<I \mid<I I I$ & $\mathrm{NW}<[(\mathrm{I}, \mathrm{II})<\mathrm{III}]$ & $(N W, I, I I)<$ III \\
\hline \multirow[t]{2}{*}{ IV } & M & $(N W, I)<(I I, I I I)$ & NW, I, II, III & $(N W, I, I I)<I I I$ \\
\hline & $\mathrm{F}$ & $N W<I<I \mid<I I I$ & $\mathrm{NW}<[(\mathrm{I}, \mathrm{II})<\mathrm{III}]$ & $N W<[(I, I I)<I I I]$ \\
\hline \multirow[t]{2}{*}{ V } & $M$ & $(N W, I)<(I I, I I I)$ & III < [(NW, I) < II] & $(N W, I, I I)<I I I$ \\
\hline & $\mathrm{F}$ & $N W<I<I \mid<I I I$ & $(\mathrm{NW}, \mathrm{I}, \mathrm{II})<\mathrm{III}$ & $N W<I<I \mid<I I I$ \\
\hline \multirow[t]{2}{*}{$\mathrm{Vl}$} & $M$ & NW, I, II, III & NW, I, II, III & NW, I, II, III \\
\hline & $\mathrm{F}$ & NW, I, II, III & NW, I, II, III & NW, I, II, III \\
\hline \multirow[t]{2}{*}{ VII } & $M$ & NW, I, II, III & NW, I, II, III & $(I, I I, I I)<N W$ \\
\hline & $\mathrm{F}$ & $(I, I I, I I)<N W$ & NW, I, II, III & NW, I, II, III \\
\hline \multirow[t]{2}{*}{ VIII } & M & $N W<[I I,(I<I I I)]$ & $(\mathrm{NW}, \mathrm{I}, \mathrm{II})<\mathrm{III}$ & $(\mathrm{NW}, \mathrm{I}, \mathrm{II})<\mathrm{III}$ \\
\hline & $\mathrm{F}$ & $N W<(I, I I, I I I)$ & $(\mathrm{NW}, \mathrm{I}, \mathrm{II})<\mathrm{III}$ & $(\mathrm{NW}, \mathrm{I}, \mathrm{II})<\mathrm{III}$ \\
\hline
\end{tabular}

same age group belonging to different classes of obesity, produced no statistically significant results, in that the scores of sensitivity and specificity were about $50 \%$ in all age groups, in males and females. The results also remained approximately the same when we added to the scores of the BUT sub-scales those of the TFEQ sub-scales and the total score of the BES.

\section{DISCUSSION}

Factor structure and internal consistency This study, using an obese population seeking treatment, confirmed an earlier one on the validity of the BUT. The same 5 -factor and 8factor models were revealed for BUT-A and BUT-B respectively.

\begin{tabular}{|c|c|c|c|c|c|c|c|c|c|}
\hline \multicolumn{10}{|c|}{$\begin{array}{c}\text { TABLE } 9 \\
\text { Discriminant analysis. }\end{array}$} \\
\hline & \multicolumn{3}{|c|}{$18-39$} & \multicolumn{3}{|c|}{$40-49$} & \multicolumn{3}{|c|}{$50-65$} \\
\hline & Sensitivity & Specificity & CC & Sensitivity & Specificity & $\mathrm{CC}$ & Sensitivity & Specificity & CC \\
\hline Males & 73.2 & 96.4 & 83.8 & 82.1 & 94.4 & 83.8 & 88.7 & 87.4 & 77.8 \\
\hline Females & 75.9 & 88.8 & 79.7 & 73.8 & 90.0 & 74.6 & 75.0 & 85.7 & 75.1 \\
\hline
\end{tabular}


When using the results of the Item-Total Correlations, and comparing to those of the Principal Components Analysis and to the levels of Cronbach's alpha coefficients, internal consistency of the scale appears good.

\section{Concurrent and discriminant validity}

The comparison between BUT-A and BUT-B showed that all the BUT-A sub-scales were correlated with the following BUT-B factors: III (stomach, abdomen, hips, thighs, knees), IV (stature, legs, ankles, feet, hands), V (arms, shoulders, chest, breast, genitals) and VIII (sweating, blushing, noises, odours and buttocks). The correlation appears understandable in that these BUT-B sub-scales are related to body parts or functions which very often cause uneasiness, worry and dissatisfaction in subjects with obesity.

The correlation with the BES appears noteworthy, in that a relevant segment of subjects with obesity experience binge eating $(47,48)$ and the links between binge eating and body shame and disparagement are well known (49-53).

By contrast, the BUT scales do not correlate with the TFEQ sub-scales. In particular, they do not correlate with the Disinhibition subscale, possibly because the Disinhibition construct may measure overeating rather than binge eating (54). Regardless the BUT is a specific questionnaire that measures different dimensions from the TFEQ.

\section{Predictive validity for gender, age and BMI}

Firstly, gender. In the entire sample of subjects with obesity, females obtained significantly higher scores than males in the GSI and in all the BUT-A and BUT-B sub-scales. These data confirm the results of our previous validation study as well as those of most studies on body image, but now for an obese population.

Then, age. With regard to the different age groups, both men and women aged 18-39 and 40-49 displayed significantly higher scores than older subjects (aged 50-65) on the GSI, the WP sub-scale, the BIC sub-scale and the BUT-B III sub-scale. This is reasonable and is in keeping with a decrease in body uneasiness with increased age. According to some researchers $(55,56)$, the more or less satisfying feelings with the image of one's body are the result of two different factors: the aesthetic judgment of one's physical appearance and the importance or salience that is attributed to it. From this point of view, older people could be aware of their objective physical defects - both from early in life and those due to aging - but they would regard these as less important than younger people do. The scores of the subscales relating to body parts and body functions appear, for the most part, not to be influenced by age.

Lastly, BMI. When comparing NW females with those with obesity we found the NW group to have lower scores, in all the age groups, in the GSI and in all the BUT-A subscales with the following exception: in the age group 50-65, the scores of NW females in the sub-scale D are significantly lower only when compared to those of females with class III obesity. Older women show more intense detachment and estrangement feelings towards their body only when they are seriously obese (BMI $>40$ ).

With regard the results for the feelings towards body parts, NW females displayed significantly lower scores than those of all females with obesity

- in the age group 18-39 in the sub-scales III, IV, $\mathrm{V}$ and VIII

- in the age group 40-49 in the sub-scales III and IV

- in the age group 50-65 in the sub-scales IV and $\mathrm{V}$, more modestly.

These data could be explained by the fact that these sub-scales are related to body parts (e.g. abdomen, thighs, legs, arms, stature) which usually cause intense uneasiness and dissatisfaction in subjects with obesity.

For the males the data are more difficult to understand. But where there are differences, for example in the age group 18-39, NW males obtained significantly lower scores than those of all males with obesity; also in the age group 40-49 NW males obtained lower scores in the BUT-A sub-scales. In both these groups the CSM sub-scale is an exception which could be explained by the fact that its scores are very scattered both in NW and obese subjects.

The data relating to the age group 50-65 were complicated and difficult to explain: in the GSI, BIC and D sub-scales NW males obtained significantly lower scores than those of males with obesity-III and, in the WP sub-scale, significantly lower scores than those of males with obesity-II and -III; on the contrary, in the A sub-scale their scores are significantly higher than those of males with obesity-I and -II.

As for the BUT-B sub-scales, in the age group 18-39 NW males obtained significantly lower scores than those of all males with obesity in the sub-scales III and VIII; in the age group 40-49 only in the sub-scale III. In this case too, the subscales where significant differences have been found are related to body parts (e.g. abdomen, chest, legs) which very often cause uneasiness 


\section{APPENDIX 1}

$\mathrm{BUT} \bullet \mathrm{A}$

Mark with an $\mathrm{X}$ the answer which best expresses your experience at the moment.

1 I spend a lot of time in front of the mirror

2 I don't trust my appearance: I'm afraid it will change suddenly

3 I like those clothes which hide my body

4 I spend a lot of time thinking about some defects of my physical appearance

5 When I undress, I avoid looking at myself

6 I think my life would change significantly if I could correct some of my aesthetic defects

7 Eating with others causes me anxiety

8 The thought of some defects of my body torments me so much that it prevents me being with others

9 I'm terrified of putting on weight

10 I make detailed comparisons between my appearance and that of others

11 If I begin to look at myself, I find it difficult to stop

12 I would do anything to change some parts of my body

13 I stay at home and avoid others seeing me

14 I am ashamed of the physical needs of my body

15 I feel I am laughed at because of my appearance

16 The thought of some defects of my body torments me so much that it prevents me studying or working

17 I look in the mirror for an image of myself which satisfies me and I continue to search until I am sure I have found it

18 I feel I am fatter than others tell me

19 I avoid mirrors

20 I have the impression that my image is always different

21 I would like to have a thin and bony body

22 I am dissatisfied with my appearance

23 My physical appearance is disappointing compared to my ideal image

24 I would like to undergo plastic surgery

25 I can't stand the idea of living with the appearance I have

26 I look at myself in the mirror and have a sensation of uneasiness and strangeness

27 I am afraid that my body will change against my will, in a way I don' like

28 I feel detached from my body

29 I have the sensation that my body does not belong to me

30 The thought of some defects of my body torments me so much that it prevents me having a sexual life

31 I observe myself in what I do and ask myself how I seem to others

32 I would like to decide what appearance to have

33 I feel different to how others see me

34 I am ashamed of my body
Never Seldom Sometimes Often Very often Always

$\begin{array}{llllll}0 & 1 & 2 & 3 & 4 & 5 \\ 0 & 1 & 2 & 3 & 4 & 5\end{array}$

0

0

0

0

0

0

0

0

0

0

0

0

0

0

0

0

0

0

0

0

0

0

0

0

0

0

0

0

1

2

3

4

5

$\begin{array}{lll}0 & 1 & 2 \\ 0 & 1 & 2\end{array}$

0 
and dissatisfaction in subjects with obesity. It also seems evident that these feelings tend to become less important with aging.

The results of the analyses of covariance showed that the statistically significant differences are mainly due, in males of all age groups, to the BMI values. In females, by con-

\section{APPENDIX 1 - (Continued) BUT•B}

Mark with an $\mathrm{X}$ the answer which best expresses your experience at the moment: of my body, in particular, I hate

Never Seldom Sometimes Often Very often Always

1 Height

2 The shape of my head

3 The shape of my face

4 Skin

5 Hair

6 Forehead

7 Eyebrows

8 Eyes

9 Nose

10 Lips

11 Mouth

12 Teeth

13 Ears

14 Neck

15 Chin

16 Moustache

17 Beard

18 Hairs

19 Shoulders

20 Arms

21 Hands

22 Chest

23 Breasts

24 Stomach

25 Abdomen

26 Genitals

27 Buttocks

28 Hips

29 Thighs

30 Knees

31 Legs

32 Ankles

33 Feet

34 Odour

35 Noises

36 Sweat

37 Blushing trast, there are not statistically significant effects of the BMI values on the scores of most of the BUT sub-scales. We could think that in females the intensity of body uneasiness is not correlated to the objective degree of obesity. Therefore, the current differentiation of obesity into three classes produces, in

\section{APPENDIX 2 SCORING}

\section{$\mathrm{BUT} \bullet \mathrm{A}$ (items 1-34)}

\section{Global measure}

GSI Global Severity Index

The average rating of all 34 items constituting the BUT•A (1-34)

\section{Subscales}

WP Weight Phobia

Average $(9+10+18+21+24+31+32+33)$

BIC Body Image Concerns

Average $(3+4+6+12+15+22+23+25+34)$

A Avoidance

Average $(5+8+13+16+19+30)$

CSM Compulsive Self-Monitoring

Average $(1+11+17+20+27)$

D Depersonalization

Average $(2+7+14+26+28+29)$

\section{BUT•B (items 1-37)}

Global measures

PST, Positive Symptom Total

The number of body parts or function rated higher than zero

PSDI, Positive Symptom Distress Index

The average rating of those items constituting the

PST, Positive Symptom Total

\section{Subscales}

BUT•B I Eyebrows, Eyes, Nose, Lips, Mouth, Teeth Average $(7+8+9+10+11+12)$

BUT•B II Head Shape, Face Shape, Forehead, Ears, Neck, Chin

Average $(2+3+6+13+14+15)$

BUT•B III Stomach, Abdomen, Hips, Thighs, Knees Average $(24+25+28+29+30)$

BUT•B IV Height, Hands, Legs, Ankles, Feet Average $(1+21+31+32+33)$

BUT•B V Shoulders, Arms, Chest, Breasts, Genitals Average $(19+20+22+23+26)$

BUT•B VI Moustache, Beard, Hairs

Average $(16+17+18)$

BUT•B VII Skin, Hair

Average (4+5)

BUT•B VIII Buttocks, Odour, Noises, Sweat, Blushing Average $(27+34+35+36+37)$ 
our opinion, weak and variable effects on body image.

In conclusion, the BUT can be a valuable multidimensional tool for the clinical assessment of body uneasiness in obesity; the scores of its sub-scales do not show a linear correlation with BMI values.

\section{Limitations}

The first limitation of this study is the absence of a general population sample of obese subjects.

Second, the absence of clinical and general population samples of overweight subjects (BMI between 25 and 29.9).

Third, it could be instructive to compare the BUT scores with those obtained by using other body image assessment tools or a diagnostic semi-structured interview, such as Body Dysmorphic Disorder Evaluation, BDDE $(57,58)$.

\section{Clinical implications and future research directions}

As for the results of the first discriminant analysis, carried out to evaluate the capacity of the BUT to single out the presence/absence of obesity, we think that the values of the sensitivity and specificity are worthy of note from the clinical point of view: first of all, we think that NW subjects with a negative body image need particular clinical attention, because they could suffer from, or could be at risk for Eating Disorders, Body Dysmorphic Disorder or Social Phobia. Secondly, subjects with obesity but without a negative body image raise a paradoxical problem: on the one hand, because of this fact their quality of life is probably better; on the other hand, however, it is well known that a negative body image could be a motivation to treatment, and that, particularly in young women, this motivation could be stronger than concern about health (36). A valuable direction for future research could be to explore this area.

In conclusion, we think that it is pertinent to use BUT as a valid and reliable multidimensional tool for the assessment of body image in obesity: it was normed and validated on a large sample of patients with class I, II and III obesity. It is readable and easy to use and requires only 15 minutes. Furthermore, BUT can help to evaluate the effect on body image both of bariatric surgery and of medical management of obesity (37).

\section{ACKNOWLEDGEMENTS}

The QUOVADIS study is supported by an unrestricted grant from BRACCO Imaging, Milano, Italy.

\section{REFERENCES}

1. Stunkard A., Mendelson M.: Obesity and the body image. I. Characteristics of disturbances in the body image of some obese persons. Am. J. Psychiatry, 123, 1296-1300, 1967.

2. Stunkard A., Burt V.: Obesity and the body image: II. Age of onset of disturbances in the body image. Am. J. Psychiatry, 123, 1443-1447, 1967.

3. Thompson JK. Body image, eating disorders and obesity. An integrative guide for assessment and treatment. Washington D.C.: American Psychological Association, 1996.

4. Thompson J., Smolak L.: Body image, eating disorders and obesity in youth. Assessment, prevention and treatment. Washington, DC: American Psychological Association, 2001.

5. Rosen J. Obesity and body image. In: Fairburn C., Brownell K. (Eds.), Eating disorders and obesity. A Comprehensive Handbook. 2nd ed. New York, Guilford, 2002, pp. 399-402.

6. Sarwer D., Thompson J.: Obesity and body image disturbance. In: Wadden T., Stunkard A. (Eds.), Handbook of obesity treatment. New York, Guilford, 2002, pp. 447-464.

7. Schwartz D., Brownell K.: Obesity and body image. In: Cash T., Pruzinsky T. (Eds.), Body image: a handbook of theory, research and clinical practice. New York, Guilford, 2002, pp. 200-209.

8. Sarwer DB, Thompson JK, Cash TF. Body image and obesity in adulthood. Psychiatr. Clin. North Am., 28, $69-87,2005$

9. Grilo C.: Eating and weight disorders. Hove, Psychology Press, 2006

10. Pruzinsky T., Cash T.: Understanding body images. Historical and conceptual perspectives. In: Cash T., Pruzinsky T. (Eds), Body image. A handbook of theory, research and clinical practice. New York, Guilford, 2002, pp. 3-12.

11. Thompson J., Penner L., Altabe M.: Procedures, problems and progress in the assessment of the body images. In: Cash T., Pruzinsky T. (Eds.), Body images assessment development and change. New York, The Guilford Press, 1990.

12. Thompson J.K.: Assessment of body image. In: Allison D.B. (Ed.), Handbook of Assessment Methods for Eating Behaviors and Weight-Related Problems. Thousand Oaks, CA., Sage, 1995. pp. 119-148.

13. Thompson J., Van den Berg P.: Measuring body image attitudes among adolescents and adults. In: Cash T., Pruzinsky T. (Eds.), Body image: A handbook of theory, research and clinical practice. New York, Guilford, 2002, pp. 142-154.

14. Secord P., Jourard S.: The appraisal of body cathexis: body cathexis and the self. J. Consult. Psychol., 17, 343347,1953

15. Cooper P., Taylor M., Cooper Z., Fairburn C.: The development and validation of the Body Shape Questionnaire (BSQ). Int. J. Eat. Disord., 6, 485-494, 1987.

16. Slade P., Dewey M., Newton T., Brodie D., Kiemle G.: Development and preliminary validation of the Body Satisfaction Scale (BSS). Psychol. Health, 4, 213-220, 1990.

17. Orlandi E., Covezzi R., Galeazzi G.M., Guaraldi G.P.: The Italian version of the Body Cathexis Scale. Eat. Weight Disord., 11, 79-84, 2006. 
18. Probst M., Vandereycken W., Van Coppenolle H., Vanderlinden J.: Body Attitude Test for patients with an eating disorder: psychometric characteristics of a new questionnaire. Eating Disorders: The Journal of Treatment and Prevention 3, 133-145, 1995.

19. Probst M., Van Coppenolle H., Vandereycken W.: Further experience with the Body Attitude Test. Eat. Weight Disord., 2, 100-104, 1997.

20. Carano A., De Berardis D., Gambi F., Di Paolo C., Campanella D., Pelusi L., Sepede G., Mancini E., La Rovere R., Salini G., Cotellessa C., Salerno R.M., Ferro F.M.: Alexithymia and body image in adult outpatients with binge eating disorder. Int. J. Eat. Disord., 39, 332340, 2006.

21. Kashima A., Yamashita T., Okamoto A., Nagoshi Y., Wada Y., Tadai T., Fukui K.: Japanese version of the Body Attitude Test: its reliability and validity. Psychiatry Clin. Neurosci., 57, 511-516, 2003.

22. Williamson D., Davis C., Bennett S., Goreczny A., Gleaves D.: Development of a simple procedure for body image assessment. Behav. Assess., 11, 433-446, 1989.

23. Veron-Guidry S., Williamson D.: Development of a body image assessment procedure for children and preadolescents. Int. J. Eat. Disord., 20, 287-293, 1996.

24. Cuzzolaro M., Vetrone G., Marano G., Garfinkel P.E.: The Body Uneasiness Test (BUT): development and validation of a new body image assessment scale. Eat. Weight Disord., 11, 1-13, 2006.

25. Rosen J.C.: Negative body image. In: Blechman E.A., Brownell K.D. (Eds.), Behavioral medicine and women. A Comprehensive Handbook. New York, The Guilford Press, p. 380-385, 1998.

26. Garner D., Garfinkel P.: The Eating Attitudes Test: an index of the symptoms of anorexia nervosa. Psychol. Med., 9, 273-279, 1979.

27. Garner D.M., Olmsted M.P., Bohr Y., Garfinkel P.E.: The Eating Attitudes Test: Psychometric features and clinical correlates. Psychol. Med., 12, 871-878, 1982.

28. Cuzzolaro M., Petrilli A.: Validazione della versione italiana dell'EAT-40 di D.M. Garner e P.E. Garfinkel. Psichiatria dell'Infanzia e dell'Adolescenza 55, 209217, 1987

29. Dotti A., Lazzari R.: Validation and reliability of the Italian EAT-26. Eat. Weight Disord., 3, 188-194, 1998.

30. American Psychiatric Association. Diagnostic and statistical manual of mental disorders, DSM-IV-TR. $4^{\text {th }}$, Text Revised ed. Washington, DC: American Psychiatric Association, 2000.

31. Ravaldi C., Vannacci A., Zucchi T., Mannucci E., Cabras P.L., Boldrini M., Murciano L., Rotella C.M., Ricca V.: Eating disorders and body image disturbances among ballet dancers, gymnasium users and body builders. Psychopathology, 36, 247-254, 2003.

32. De Berardis D., Campanella D., Gambi F., Sepede G., Carano A., Pelusi L., La Rovere R., Di Matteo D., Salini G., Cotellessa C., Salerno R.M., Ferro F.M.: Alexithymia and body image disturbances in women with Premenstrual Dysphoric Disorder. J. Psychosom. Obstet. Gynaecol., 26, 257-264, 2005.

33. De Panfilis C., Rabbaglio P., Rossi C., Zita G., Maggini C.: Body image disturbance, parental bonding and alexithymia in patients with eating disorders. Psychopathology, 36, 239-246, 2003.

34. Cena H., Toselli A., Tedeschi S.: Body uneasiness in overweight and obese Italian women seeking weightloss treatment. Eat. Weight Disord., 8, 321-325, 2003.

35. Dalle Grave R., Calugi S., Magri F., Cuzzolaro M.,
Dall'Aglio E., Lucchin L., Melchionda M., Marchesini G., QUOVADIS study group: Weight loss expectations in obese patients seeking treatment at medical centers. Obes. Res., 12, 2005-2012, 2004.

36. Dalle Grave R., Calugi S., Molinari E., Petroni M.L., Bondi M., Compare A., Marchesini G., QUOVADIS Study Group: Weight loss expectations in obese patients and treatment attrition: an observational multicenter study. Obes. Res., 13, 1961-1969, 2005.

37. Dalle Grave R., Cuzzolaro M., Calugi S., Tomasi F., Temperilli F., Marchesini G.: The effect of obesity management on body image in patients seeking treatment at medical centers. Obesity (accepted for publication).

38. Gormally J., Black S., Daston S., Rardin D.: The assessment of binge eating severity among obese persons. Addict. Behav., 7, 47-55, 1982.

39. Stunkard A., Messick K.: The Three Factor Eating Questionnaire to measure dietary restraint, disinhibition and hunger. J. Psychosom. Res., 29, 71-81, 1985.

40. Melchionda N., Marchesini G., Apolone G., Cuzzolaro M., Mannucci E., Grossi E.: The QUOVADIS Study: features of obese Italian patients seeking treatment at specialist centers. Diab. Nutr. Metab., 16, 115-124, 2003.

41. World Health Organization. Preventing and managing the global epidemic. WHO Consultation on obesity. Geneva, World Health Organization, 1997.

42. National Heart Lung and Blood Institute, (NHLBI), North American Association for the Study of Obesity, (NAASO). Practical Guide to the identification, evaluation and treatment of overweight and obesity in adults. Bethesda, National Institutes of Health, 2000.

43. Weinsier R., Kushner R.: Clinical assessment of obese patients. In: Fairburn C., Brownell K., (Eds.), Eating disorders and obesity. A comprehensive handbook. $2^{\text {nd }}$ ed. New York, Guilford, 2002, pp. 512-517.

44. Cuzzolaro M., Vetrone G., Marano G., Battacchi MW.: BUT: una nuova scala per la valutazione del disagio relativo all'immagine del corpo. Psichiatria dell'Infanzia e dell'Adolescenza 66, 417-428, 1999.

45. Cuzzolaro M., Vetrone G., Marano G., Battacchi M.: Body Uneasiness Test (BUT) [Codice di identificazione: \#768]. In: Conti L. (Ed.), Repertorio delle scale di valutazione in psichiatria. Firenze, SEE, 2000, pp. 1759-1761.

46. Nunnally J.: Psychometric theory. $2^{\text {nd }}$ ed. New York, McGraw-Hill, 1978.

47. Ramacciotti C.E., Coli E., Passaglia C., Lacorte M., Pea E., Dell'Osso L.: Binge eating disorder: prevalence and psychopathological features in a clinical sample of obese people in Italy. Psychiatry Res., 94, 131-138, 2000.

48. Dingemans A.E., Bruna M.J., van Furth E.F.: Binge eating disorder: a review. Int. J. Obes. Relat. Metab. Disord., 26, 299-307, 2002.

49. Masheb R.M., Grilo C.M., Brondolo E.: Shame and its psychopathologic correlates in two women's health problems: binge eating disorder and vulvodynia. Eat. Weight Disord., 4, 187-193, 1999.

50. Guisado Macias J.A., Vaz Leal F.J.: Psychopathological differences between morbidly obese binge eaters and non-binge eaters after bariatric surgery. Eat. Weight Disord., 8, 315-318, 2003.

51. Masheb R.M., Grilo C.M.: Quality of life in patients with binge eating disorder. Eat. Weight Disord., 9 , 194-199, 2004.

52. Vander Wal J.S.: Eating and body image concerns among average-weight and obese African American and Hispanic girls. Eat. Behav., 5, 181-187, 2004.

53. Reas D.L., Grilo C.M., Masheb R.M., Wilson G.T.: 
Body checking and avoidance in overweight patients with binge eating disorder. Int. J. Eat. Disord., 37, 342-346, 2005

54. Smith C.F., Geiselman P.J., Williamson D.A., Champagne C.M., Bray G.A., Ryan D.H.: Association of dietary restraint and disinhibition with eating behavior, body mass, and hunger. Eat. Weight Disord., 3, 7-15, 1998.

55. Muth J., Cash T.: Body image attitudes: what difference does gender make? J. Appl. Soc. Psychol., 27, 1438-1452, 1997.

56. Whitbourne S., Skultety K.: Body image development.
Adulthood and aging. In: Cash T., Pruzinsky T., (Eds.), Body image. A handbook of theory, research and clinical practice. New York, Guilford, 2002, pp. 83-90.

57. Rosen J.C., Reiter J.: Development of the body dysmorphic disorder examination. Behav. Res. Ther., 34, 755766, 1996.

58. Cuzzolaro M., Aveni F.: Versione italiana e adattamento dell'intervista: Body Dysmorphic Disorder Examination (BDDE) di J.C. Rosen e J.L. Reiter [Codice di identificazione: \#767]. In: Conti L. (Ed.), Repertorio delle scale di valutazione in psichiatria. Firenze, SEE, 2000, pp. 1723-1757. 